\title{
Model Latihan Strokes Bulutangkis Untuk Atlet Single Usia Pemula
}

\author{
Muhamad Ridwan ${ }^{a^{*}}$, Firmansyah Dlis $^{b}$, Hidayat Humaid ${ }^{c}$ \\ ${ }^{a, b, c}$ Universitas Negeri Jakarta, Jalan Rawamangun Muka, Jakarta 13220, Indonesia
}

*Corresponding author: muhamad55ridwan@gmail.com

\author{
A R T I C LE IN F O \\ Article history: \\ Received : 08 Mei 2018 \\ Received in revised \\ form : 18 Juni 2018 \\ Accepted : 22 \\ September 2018 \\ Keywords: Badminton \\ Strokes, Exercise \\ Model, Single Player.
}

\begin{abstract}
A B S T R A C T
This study aims to develop a model of badminton strokes training for junior single player in improving the skills of badminton strokes. Research method used in this research is research development method $(R \& D)$. This study was conducted in PB. Kurnia Tasikmalaya with 35 research subjects. Analyzed using paired sample t test. The result of the analysis showed that the average value of the result of the badminton strokes training before the treatment of the training model was 77,57 and after being treated with the exercise model was 88,89 it means that there was an increase in the mean value and in the difference significance test with SPSS 23 got the result $t=18,920 \mathrm{df}=34$ and $p$ value $=0,000<0,05$ which means there is significant difference of badminton strokes training before and after the treatment of strokes training model. Thus the model of badminton strokes training for junior single player is effective to improve the skills of badminton strokes.
\end{abstract}

\section{PENDAHULUAN}

Bulutangkis merupakan salah satu cabang olahraga populer di Indonesia, bahkan di dunia. Olahraga ini sangat digemari oleh berbagai kalangan, mulai anak-anak hingga orang dewasa karena permainan bulutangkis menarik dan relatif mudah untuk dimainkan. Untuk bermain bulutangkis tentu ada teknik-teknik dasar yang harus diketahui dan dikuasai diantaranya yaitu sikap berdiri (stance), teknik memegang raket (grip), teknik langkah kaki (footwork), dan teknik memukul bola (strokes).

Strokes atau pukulan merupakan inti dari permainan bulutangkis karena setelah posisi stance, pegangan grip dan footwork untuk mengejar shuttlecock tetap seorang pemain bulutangkis harus menguasai teknik pukulan untuk mengembalikan pukulan lawan. Dalam permainan bulutangkis teknik sering digunakan adalah lob, smash, dan dropshot. The three most popular strokes are the smash, the clear and the drop (Seth, 2016).

Pukulan lob sangat penting dalam mengendalikan permainan bulutangkis, sangat baik untuk mempersiapkan serangan atau untuk membenahi posisi sulit saat mendapat tekanan dari lawan. Pukulan smash adalah pukulan menyerang yang menukik tajam kearah pertahanan lawan.
Pukulan smash sangat berpeluang untuk mencetak poin oleh karena itu sangat penting seorang atlet bulutangkis menguasai pukulan smash yang tajam dan kencang karena bisa dijadikan senjata untuk mematikan lawan dan memenangkan pertandingan. Sedangkan, pukulan dropshot adalah pukulan yang mengiris shuttlecock dan mengutamakan feeling agar shuttlecock tipis di atas net dan jatuh di daerah depan lapangan lawan. Ketiga pukulan tersebut mutlak harus dikuasai oleh seorang atlet bulutangkis,

Kesulitan anak saat melakukan adalah kecepatan dan ketepatan langkah dengan ketepatan saat melakukan pukulan. oleh karena itu, hal ini harus menjadi perhatian jikalau kualitas pukulan si atlet sangat kurang, baik kurang dalam hal konsep gerak, ketepatan dan teknik memukul itu sendiri, karena itu harus ada bentuk atau model latihan yang lebih baik agar kualitas pukulan lob, smash, dan dropshot meningkat. Hasil observasi yang saya lihat di salah satu klub di Kota Tasikmalaya yaitu klub bulutangkis PB. Kurnia Tasikmalaya, atlet di klub tersebut perlu diberikan latihan yang lebih baik dan bervariatif karena latihan yang monoton, kurang menarik sehingga berdampak pada kurangnya kualitas pukulan dari segi teknik dan ketepatan dan tujuannya pun tidak tercapai. 
Pelatih sudah menerapkan model latihan pukulan lob, smash, dan dropshot tetapi model latihan yang diterapkan masih sedikit, kurang memberikan variasi dalam latihan dan belum melakukan pengembangan latihan yang sesuai dengan perkembangan olahraga bulutangkis saat ini. Untuk itu, perlu adanya pengembangan modelmodel latihan lob, smash, dan dropshot yang baru yang lebih variatif sehingga dapat meningkatkan kualitas strokes atlet lebih baik lagi.

Pukulan lob merupakan pukulan yang sering dilakukan oleh pemain bulutangkis, karena pukulan $l o b$ berfungsi untuk mengendalikan pertandingan tetapi lob juga bisa menjadi pukulan yang menyulitkan lawan sehingga bisa untuk mempersiapkan penyerangan. Pukulan $l o b$ dapat dilakukan dari atas kepala (overhead) atau dari bawah (underarm) baik dari sisi forehand maupun backhand. The overhead forehand and backhand clear strokes were subject to the analysis. These strokes provide the basis of playing the shuttle from the player's own backline to the opponent's backline and are among the most common and important of all badminton strokes (Sorensen, Zee, dan Rasmussen, 2011).

Pukulan smash merupakan pukulan yang kencang dan menukik tajam ke area pertahanan lawan. In the stroke, the shuttle is hit toward the opponent's court with high speed and at a steep downward angle (Zhang et al., 2016). Pukulan ini biasanya dilakukan dengan sekuat tenaga supaya lawan kesulitan dalam mengembalikan shuttlecock tersebut. Namun, keterampilan ini diharuskan adanya kecepatan, ketepatan dan kordinasi dalam setiap gerakan nya. Ketepatan dalam lompatan dan pukulan merupakan kunci dari sukses nya pukulan smash. Smashing performance is a key factor to winning points during the badminton game and commonly used from different positions and places on the court (Hassan, 2017).

Pukulan dropshot termasuk pukulan overhead yang mengutamakan feeling saat mengiris shuttlecock agar shuttlecock tepat tipis di atas net dan jatuh di depan permainan lawan. In badminton, one variation of the 'drop shot' involves the player, in a linear motion, gently 'push' the shuttlecock using the racquet to give it enough speed for it to travel just over the net and into the opponent's court (Ongvises dan Xu, 2013). Pukulan ini biasanya dibarengi dengan pukulan tipuan, karena posisi seperti akan melakukan smash tetapi bukan. Pukulan ini lebih banyak membutuhkan perasaan agar shuttlecock jatuh tipis di atas net, sehingga sulit di jangkau lawan (Subarjah dan Satriya, 2013). Pukulan ini perlu teknik tingkat tinggi untukmenguasainya perlu latihan yang berulangulang supaya mendapatkan gerakan yang pas dan tenaga yang dikeluarkan tepat.

\section{METODE PENELITIAN}

Penelitian pengembangan model latihan strokes bulutangkis untuk atlet single usia pemula, pemula disini yaitu pemula kategori umur yaitu U-15 dan strokes disini yaitu strokes lob, smash, dan drosphot. secara khusus memilki beberapa tujuan yaitu: 1. Mengembangkan suatu rancangan model latihan strokes bulutangkis. 2. Memperoleh data empiris tentang efektivitas hasil pengembangan model latihan strokes bulutangkis. Tujuan akhir dari penelitian pengembangan ini adalah untuk menghasilkan produk buku model latihan strokes bulutangkis yang dapat memberikan manfaat pada pelatih untuk mempermudah pelatih dalam menerapkan materi latihan. Sehingga nantinya dapat digunakan untuk meningkatkan kualitas dan akurasi teknik dasar bulutangkis agar efektif, efisien, dan menarik.

Penelitian dan pengembangan (research \& development) adalah metode penelitian yang digunakan untuk menghasilkan produk baru, menguji keefektifan produk yang telah ada, serta mengembangkan dan menciptakan produk baru (Sugiyono, 2015). Penelitian dan pengembangan model latihan Strokes untuk atlet single usia pemula ini menggunakan model pegembangan Research \& Development $(R \& D)$ dari Borg and Gall yang terdiri dari sepuluh langkah: 1. Research and information,

2. Planning, 3. Develop preliminary form of product, 4. Preliminary field testing, 5. Main product revision, 6. Main field testing, 7. Operational product revision, 8. Operational field testing, 9. Final product revision, 10. Dissemination and implementation (Borg\&Gall, 2007). Pendekatan yang digunakan dalam penelitian ini adalah pendekatan kualitatif dan kuantitatif. Penelitian dilaksanakan di PB. Mitra Jaya Tasikmalaya (Uji Kelompok Kecil) dengan subyek 15 orang dan di klub PB. Kurnia 
Tasikmalaya (Uji kelompok besar dan uji efektifitas) dengan subyek 35 orang, verifikasi produk oleh 3 ahli bulutangkis sekaligus berprofesi sebagai dosen. dan waktu yang diperlukan dalam penelitian dan pengembangan dengan mengacu pada penelitian dan pengembangan dari Borg and Gall yaitu 3 bulan. Penelitian ini dianalisis menggunakan paired sample t test.

\section{HASIL}

Hasil pengembangan model latihan strokes bulutangkis untuk atlet single usia pemula ditulis dalam bentuk naskah/modul yang disajikan dalam bentuk-bentuk/gambar beserta pola latihan strokes bulutangkis untuk atlet single Usia Pemula.

Draft model pertama sebelum di validasi oleh pakar/ahli model latihan strokes bulutangkis ini sebanyak 100 item model. Setelah di validasi oleh 3 ahli/pakar dan mengalami revisi, jumlahnya menjadi 90 item model yang layak untuk di ujicobakan pada kelompok kecil.

Hasil Ujicoba kelompok kecil dari 90 item model latihan strokes bulutangkis terhadap 15 atlet PB. Mitra Jaya Tasikmalaya. 90 item model tersebut dapat diterapkan dan hanya mengalami sedikit revisi. Setelah diujicobakan dalam sakala kecil maka selanjutnya adalah mengujicobakan prouk pada kelompok besar sekaligus uji efektifitas pada klub bulutangkis PB. Kurnia Tasikmalaya dengan subyek penelitian sebanyak 35 orang.

Untuk mengetahui keefektifan produk, penelitian menggunakan instrument tes keterampilan strokes (lob,smash,dropshot) bulutangkis agar mendapatkan hasil pretest sebelum diberi perlakuan model latihan strokes bulutangkis daan hasil posttest setelah diberi perlakukan model latihan strokes bulutangkis.

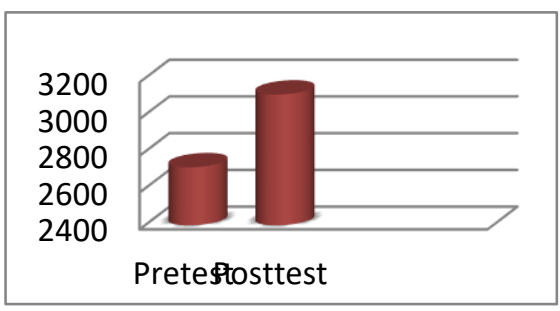

Gambar 1: Peningkatan nilai pretest dan posttest
Hasil pretest sebelum diberikan perlakuan adalah 2715 dengan rata-rata 77,57 dan standar deviasi 5,837 sedangkan hasil posttest setelah diberikan perlakuan adalah 3111 dengan rata-rata 88,89 dan standar deviasi 6,581 .

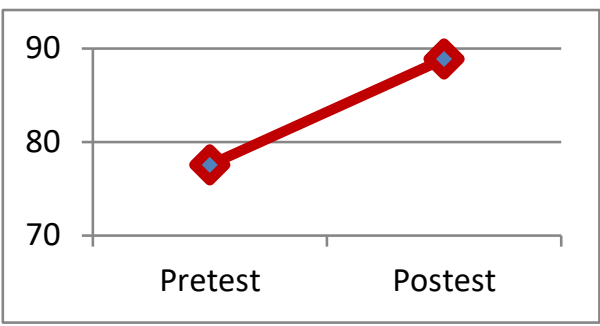

\section{Gambar 2: Peningkatan nilai rata-rata pretest dan posttest}

Dapat diartikan bahwa keterampilan strokes bulutangkis terdapat peningkatan yang signifikan.

Hasil analisis paired sample $t$ test dengan SPSS23 didapat hasil t-hitung $=18,920, \mathrm{df}=34 \mathrm{dan}$ p-value $=0.00<0,05$, ini berarti dalam model latihan strokes bulutangkis sebelum dan sesudah diberikannya perlakuan terdapat adanya perbedaan yang signifikan. Dengan demikian dapat disimpulkan bahwa model latihan strokes bulutangkis untuk atlet single usia pemula yang sudah dikembangkan, efektif dan dapat meningkatkan keterampilan strokes bulutangkis.

Model latihan strokes bulutangkis untuk atlet single usia pemula (u-15) ini bertujuan sebagai media alat bantu bagi pelatih pada saat menyampaikan materi strokes, meningkatkan kemampuan strokes dan juga sebagai referensi tambahan dalam melatih.

Keunggulan dari produk ini adalah Meningkatkan keterampilan strokes bulutangkis pada atlet single usia pemula, variasi latihan dapat menjadikan anak lebih aktif dalam melakukan latihan strokes bulutangkis, model latihan strokes bulutangkis ini lebih efektif dan efisien, Sebagai referensi bagi pelatih dalam menerapkan model latihan strokes untuk atlet single usia pemula, model latihan disajikan secara sistematis.

\section{SIMPULAN DAN REKOMENDASI}

Produk model latihan strokes bulutangkis untuk atlet single usia pemula ini dinyatakan layak dan efektif untuk digunakan pada saat latihan di klub bulutangkis. Produk ini menyajikan model-model 
latihan strokes bulutangkis yang sistematis (dari yang mudah ke yang sukar) model latihan yang menekankan pada proses gerakan pukulan lob, proses gerakan langkah $l o b$, proses gerakan langkah serta pukulan $l o b$, dan latihan drill $l o b$ dengan target. Dan model latihan smash dan dropshot, model latihan yang menekankan pada gerakan smash, gerakan langkah, lompatan, ketepatan pukulan, serta drill smash menggunakan target. Begitu juga model latihan dropshot yang menekankan pada proses gerakan dropshot, ketepatan pukulan serta gerak langkah, dan menekankan model latihan dropshot menggunakan target yang semuanya bentuk latihan nya sesuai dengan karakteristik usia pemula (u-15). Tentu dalam penerapannya harus dengan penjelasan pelatih agar, anak bisa mengerti maksud dan tujuan dari latihan tersebut serta pelatih harus selalu mengoreksi jika ada anak yang melakukan kesalahan gerakan karena itu adalah salah satu ciri khas latihan teknik.

Diharapkan produk ini dapat menjadi bahan masukan dan referensi bagi pelatih untuk menerapkan variasi latihan dengan model latihan yang tersaji dalam produk ini.

\section{DAFTAR PUSTAKA}

Gall, Meredith D., Joyce P. Gall, dan Walter R. Borg, (2007). Educational Research Eight Edition. Pearson, USA.

Hassan, Ibrahim Hamed Ibrahim. (2017)."The Effect of Core Stability Training On Dynamic Balance and Smash Stroke Performance in Badminton Players". International Journal of Sport Science and Physical Education, Vol. 2 No. 3, hh. 44-52.

Ongives, Ampharin., Xu, Xiaoyu. (2013). "Shuttlecock Velocity Of Badminton Dropshot". ISB Journal of Science, 2013. Volume 7, h. 1.

Seth, Bipasa. (2016). "Determination Factors of Badminton Game Performance". International Journal of Physical Education, Sports and Health, IJPESH. 3 (1), IJPESH 2016, hh. 2022.
Sorensen, Kasper., Mark de Zee, dan John Rasmussen. (2011). "A Biomechanical Analysis Of Clear Strokes In Badminton Executed By Youth Players Of Different Skill Levels". ISB Brussels 2011, h. 1.

Subarjah, Herman., Satriya. (2013). Kepelatihan Permainan Bulutangkis. CV. Nurani, Bandung.

Sugiyono. (2015). Metode Penelitian dan Pengembangan (Research and Development/R\&D). Alfabeta, Bandung.

Zhang, Zhao., Shiming Li., Bingjun Wan., Peter Visentin., Qinxian Jiang., Mary Dyck., Hua Li., dan Gongbin Shan . (2016). "The Influence of X-Factor (Trunk Rotation) and Experience on the Quality of the Badminton Forehand Smash". Journal Of Human Kinetics, 2016. Volume 53, h. 9-10. 